\title{
Dos eventos documentados aos documentos manejados: A política de saúde mental brasileira em disputa
}

From documented events to managed documents: the Brazilian mental health policy in dispute

\section{Lilian Leite Chaves}

\section{(2) OpenEdition Journals}

\section{Edição electrónica}

URL: http://journals.openedition.org/aa/3282

DOI: $10.4000 /$ aa. 3282

ISSN: 2357-738X

\section{Editora}

Programa de Pós-Graduação em Antropologia Social (UnB)

\section{Edição impressa}

Data de publição: 1 dezembro 2018

Paginação: 261-284

ISSN: 0102-4302

\section{Refêrencia eletrónica}

Lilian Leite Chaves, «Dos eventos documentados aos documentos manejados: A política de saúde mental brasileira em disputa», Anuário Antropológico [Online], v.43 n.2 | 2018, posto online no dia 26 maio 2019, consultado o 28 abril 2021. URL: http://journals.openedition.org/aa/3282 ; DOI: https:// doi.org/10.4000/aa.3282

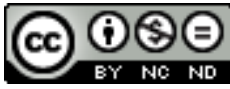

Anuário Antropológico is licensed under a Creative Commons Atribuição-Uso Não-Comercial-Proibição de realização de Obras Derivadas 4.0 International. 


\title{
Dos eventos documentados aos documentos manejados: A política de saúde mental brasileira em disputa
}

\author{
Lilian Leite Chaves
}

UFRN

\section{Introdução}

Na quinta-feira, dia 10 de dezembro de 2015, durante uma audiência com entidades da sociedade civil, o então recém Ministro da Saúde Marcelo Castro anunciou uma mudança na "Coordenação de Saúde Mental, Álcool e outras Drogas” referente à indicação de Valencius Wurch Duarte Filho para o cargo de coordenador geral, ocupado à época por Roberto Tykanori Kinoshita. Eu tomei conhecimento do ocorrido, na manhã do dia 11 de Dezembro, através de uma postagem da página "Memória da Reforma Psiquiátrica Brasil e Itália" no Facebook. Tal postagem, que me fez atinar para uma troca de gestores que saía do âmbito das alterações corriqueiras e nem sempre alardeadas, não era somente uma notícia e, sim, uma reação que se iniciava com uma pergunta seguida de um aviso em caixa alta: "O que vamos fazer?! REFORMA PSIQUIÁTRICA EM RISCO...”.

A postagem descrevia a indicação de Valencius Wurch como "o ataque mais grave impetrado à Reforma Psiquiátrica" e explicava que Valencius era "ex-diretor do maior hospício da América Latina”, a casa de saúde Doutor Eiras em Paracambi, Rio de Janeiro. Acrescentava-se à biografia do profissional a qualificação de "um dos articuladores mais ardilosos da contra reforma” o seu envolvimento com empresários da saúde, incluindo o proprietário da Casa de Saúde Doutor Eiras, gerenciada pelo profissional durante a década de 1990. Em contrapartida, Roberto Tykanori foi definido como "o primeiro interventor de um hospício (que o fechou - Casa de Saúde Anchieta em Santos) responsável pelo primeiro programa de saúde mental em liberdade”. A postagem foi finalizada com a hashtag “\#hospícionuncamais” e com a convocação "Vamos juntos lutar” (Memória da Reforma Psiquiátrica Brasil e Itália, 2015).

Essa postagem sugere ao leitor uma polarização existente no campo da saúde mental, e delineia essa polarização a partir das trajetórias dos gestores e das suas posições no cenário de construção da reforma psiquiátrica. Devido a ela, direcionei a minha atenção para as diversas postagens sobre o assunto que se avolumaram no feed de notícias da minha conta no Facebook e percebi que a nomeação do gestor 
gerou uma disputa a respeito da condução da política de saúde mental. Esta disputa ganhou forma, por um lado, com as reações daqueles que consideravam Valencius como incompatível ao cargo devido a sua trajetória como diretor de manicômio; por outro lado, com as contrarreações daqueles que o apoiavam, conferindo-lhe a competência para avaliar e aperfeiçoar a política de saúde mental. As reações e contrarreações consistem em notas públicas de entidades e associações, nota pública do Ministério da Saúde, manifestações nos diversos municípios brasileiros, ocupação da sala da Coordenação Geral de Saúde Mental em Brasília, e entrevistas com o gestor nomeado.

Tanto as reações quanto as contrarreações ganharam divulgação na grande mídia, o que fez com que a reforma psiquiátrica entrasse novamente na arena dos debates políticos de ampla divulgação. Além dos jornais, as redes sociais, especificamente o Facebook, se configuraram como um espaço de ação e repercussão política, importante para que as mobilizações alcançassem adesões e demonstrassem capilaridade. Seguindo as reações e contrarreações pela internet, através dos jornais, da rede social e das notas, tenta-se mostrar como se estrutura e justifica a disputa em torno da política nacional de saúde mental, enfatizando a existência de um movimento marcado pela documentação de eventos e pelo manejo de documentos. À luz das reflexões antropológicas sobre documentos, busca-se mostrar como eles são construídos e performados na defesa de posições.

\section{As reações a Valencius}

Das reações contrárias à indicação de Valencius, devido à quantidade de curtidas e compartilhamentos nas redes sociais e à divulgação em jornais da grande mídia, destacam-se: a nota assinada por diversas entidades e direcionada à presidente do Conselho Nacional de Saúde; a manifestação “Abraça a RAPS” e a "Ocupação Fora Valencius”. Após o comunicado do Ministro, representantes de diversas entidades - dentre elas, a ABRASCO / Associação Brasileira de Saúde Coletiva, a ABRASME/Associação Brasileira de Saúde Mental, o CFP/Conselho Federal de Psicologia, o CEBES/Centro Brasileiro de Estudos e Saúde, o IMS-UERJ/Instituto de Medicina Social da Universidade Estadual do Rio de Janeiro, o MNLA/Movimento Nacional da Luta Antimanicomial e a RENILA/Rede Nacional Internúcleos da Luta Antimanicomial - elaboraram uma nota que foi encaminhada à Maria do Socorro de Souza/Presidente do Conselho Nacional de Saúde e apresentada ao Ministro Marcelo Castro. 
A Nota Pública contra a nomeação de Valencius Wurch foi estruturada em seis tópicos nos quais se esclareciam os motivos que levavam à rejeição ao profissional. Os motivos podem ser sintetizados em: 1) a ocupação do cargo de Diretor técnico da Casa de Saúde Doutor Eiras em Paracambi e a sua posição contrária ao Projeto de Lei 3.657, de 1989, base para a lei 10.216 de 2001 que dá as diretrizes para a Política Nacional de Saúde Mental; 2) a contextualização da Casa Doutor Eiras como o maior hospital psiquiátrico privado da América Latina no qual foram constatadas violências típicas dos grandes manicômios, como a aplicação da eletroconvulsoterapia, a falta de alimentos e a internação prolongada; 3 ) a crítica ao perfil do profissional, considerando a sua atuação em hospital psiquiátrico e ressaltando que, de acordo com a lei 10.216 de 2001 e a portaria 3.088 de 2011, o hospital psiquiátrico não encontra mais lugar na rede de atenção psicossocial; 4) a contestação da autoridade científica de Valencius em razão da sua baixa produção de artigos nos campos da psiquiatria e da saúde mental; 5) A ameaça à continuidade da Política Nacional de Saúde Mental, ancorada na garantia dos direitos humanos e no cuidado territorial e comunitário; e 6) o pedido à Casa Civil para sobrestar a nomeação, preservando a continuidade da política de saúde mental sustentada no diálogo do governo com trabalhadores, usuários, familiares, gestores e acadêmicos (ABRASCO et al., 2015).

Os jornais da grande imprensa ressaltaram a perplexidade contida na Nota relativa à nomeação de um profissional com a trajetória de diretor de hospital psiquiátrico para conduzir a Política Nacional de Saúde Mental. Cambricoli (2015), para o jornal O Estado de São Paulo, o Estadão, e Chaib (2015), para o Correio Braziliense, pontuaram que a história de Valencius não era condizente com a Reforma Psiquiátrica calcada na eliminação dos manicômios e na reinserção social do paciente. Filho (2015a), em sua matéria para O Globo, traçou um quadro da situação desumana encontrada na Casa Doutor Eiras - "pacientes esquálidos, medicações inadequadas e internações indevidas” -, situando melhor a rejeição a Valencius e ilustrando a preocupação com o progresso da política de saúde mental. Formenti (2015), para o jornal Estadão, ressaltou que os críticos "temem pela volta de uma assistência centrada nas internações".

O “Abraça a RAPS” foi convocado por meio das redes sociais e teve divulgação na imprensa. O jornal “O Globo” noticiou a manifestação como um abraço simbólico em todos os Centros de Atenção Psicossocial/CAPS do país, um abraço em toda a Rede Atenção Psicossocial/RAPS (Brunet, 2015a), O evento ocorreu no dia 14 de dezembro e, como informou uma das páginas participantes, "aconteceu em todos 
os rincões do Brasil, onde existem trabalhadores, usuários, familiares da RAPS e sociedade em geral que se preocupam com o retorno dos manicômios e defendem os avanços da Reforma Psiquiátrica que vêm sendo efetivados pelo atual Coordenador Nacional Roberto Tykanori” (Abraçaço, 2015).

A capilaridade do "Abraça a RAPS” foi demonstrada em postagens que utilizaram as hashtags “\#AbraçaaRaps” "\#AbraçaRAPS”. Dessa maneira, as ações realizadas nos CAPS e em outros serviços de atenção à saúde mental foram documentadas por fotos, vídeos e relatos e compartilhadas usando um mecanismo que permitia vê-las integradas, amenizando as distâncias geográficas e dando corpo a uma mobilização nacional. Uma profusão de hashtags surgiu nesse período, como “\#FicaTyKa”, “\#ForaValencius”, “\#ManicômioNuncaMais”, “\#PorUmaSociedadeSemManicômios". Algumas continham termos que remetiam diretamente à troca dos gestores e outras resgatavam lemas já bem solidificados da luta antimanicomial.

A Ocupação Fora Valencius surgiu no dia 15 de Dezembro quando integrantes de movimentos da luta antimanicomial, trabalhadores, familiares e usuários da RAPS ocuparam a sala da Coordenação Geral de Saúde Mental, Álcool e outras drogas na cidade de Brasília. Filho (2015b) contextualizou que "com cartazes e palavras de ordem, eles protestaram contra a nomeação do psiquiatra Valencius Wurch”. A reivindicação principal da ocupação era o pedido de exoneração de Valencius por considerá-lo um defensor dos manicômios.

Os ocupantes fizeram da sala um acampamento no qual realizaram rodas de conversa, aulas, atividades culturais, intervenções e proposições de melhores diretrizes para atenção em saúde mental, estas denominadas de "portarias”. As ações foram documentadas com fotos, vídeos e boletins diários da ocupação e tais materiais foram compartilhados na página "Ocupação Valente" no Facebook, criada para a ocupação. Nessa página, foram divulgados, ainda, textos, depoimentos de personalidades, cartas de apoio de entidades, moções de repudio a Valencius, vídeos de audiências, filmes, notícias, memes e charges. Desse modo, as atividades ocorriam in loco na sala ocupada e também nas redes, numa estratégia de estendê-la a todos que acompanhavam, curtiam e compartilhavam as postagens e também se solidarizavam fazendo doações no local ou na conta bancária disponibilizada.

Os ocupantes, denominados de "valentes", permaneceram na sala da coordenação até o dia 15 de Abril quando foram retirados pela Polícia Federal. No período de Dezembro a Abril, a ocupação recebeu caravanas de vários lugares do Brasil e conclamou manifestações pelo país. A página no Facebook passou a contar com a 
documentação dessas manifestações, mostrando que a Ocupação ocorria na sala, na Esplanada, na rede e nos diversos municípios brasileiros. Numa postagem em que se divulgava um cartaz de apoio a ocupação, vê-se, claramente, a busca por essa amplitude: "Gente! Fizemos um cartaz de apoio para a ocupação. Imprimam e colem no trabalho, na escola, nas paradas de ônibus... vamos ocupar a cidade com a nossa luta!". No cartaz estava escrito em caixa alta "TODO APOIO À OCUPAÇÃO. EM DEFESA DA SAÚDE MENTAL E PELA SAÍDA IMEDIATA DE VALENCIUS WURCH". Em letras menores, afirmava-se que "Wurch representa um retrocesso nos direitos humanos e na luta antimanicomial” (Ocupação Valente, 2015). Fotos com pessoas portando este cartaz também compuseram o rol de ações que ajudavam a ampliar a ocupação.

\section{As contrarreações}

As entidades e coletivos a favor da nomeação de Valencius só se posicionaram depois que a reação contrária a ele já estava desencadeada, por isso as suas ações são denominadas aqui como contrarreações. Das ações a favor de Valencius, serão destacadas: a nota pública do Ministério da Saúde na qual o órgão justifica e mantém a sua escolha, a nota publicada pela Associação Brasileira de Psiquiatria/ABP juntamente com outras entidades, e entrevistas com o gestor. As notas de apoio a Valencius também tiveram repercussão nos jornais da grande imprensa.

O Ministério da Saúde publicou a "Nota à Imprensa" (Brasil, 2015) afirmando que a escolha do novo coordenador não fugia aos esforços do governo federal de, em consonância com a lei 10.216, impulsionar um modelo humanizado, voltado para a reinserção social, a reabilitação e a promoção dos direitos humanos. De forma esquemática, a nota foi estruturada em dois eixos: a maneira como o Ministério interpretava a política de saúde mental e, simultaneamente, a lei 10.216; e as qualidades que faziam de Valencius um nome condizente com o cargo.

A nota afirma que o objetivo da Política Nacional de Saúde Mental é consolidar um modelo aberto e de base comunitária, no qual o foco não é mais a hospitalização/segregação. Acrescenta que a Reforma Psiquiátrica é uma conquista do setor e a sua implementação é garantida por lei que "prevê assistência multiprofissional e estruturas adequadas para a complexidade do setor, o que requer desde a atenção ambulatorial até os leitos de retaguarda nos hospitais" (Brasil, 2015). No que tange às qualidades do gestor, Valencius é avaliado como alguém qualificado para reforçar essa política, pois participou das discussões que culminaram na reforma psiquiá- 
trica. Ressaltou-se, ainda, que o profissional atuava há trinta e três anos na saúde pública, havia trabalhado em prol da humanização do atendimento na Casa de Saúde Doutor Eiras, e tinha inserção acadêmica como professor de Psiquiatria e coordenador de Internato e Residência da Universidade Federal Fluminense.

Para o jornal Folha de São Paulo, Collucci (2015) noticiou como "técnica" e Cancian (2015) como "neutra” a escolha de Valencius. As reportagens de Cancian (2015) para a Folha e Formenti (2015) para o Estadão ressaltaram a ligação universitária entre Marcelo e Valencius (o último havia sido aluno do primeiro na Universidade Federal Fluminense) e as falas do Ministro sobre a neutralidade, a participação na reforma psiquiátrica e a competência do psiquiatra nomeado para realizar o balanço e o aperfeiçoamento da política. Cancian (2015), concernente ao balanço e aperfeiçoamento da política de saúde mental, enfatizou uma fala na qual o Ministro contextualiza o cenário e marca a sua posição: "Psiquiatria é uma ciência. Vamos fazer tudo para não ficar numa posição radical. Hoje na Psiquiatria temos dois grupos se digladiando. E isso não é bom para a saúde mental e o interesse do paciente. Se há alguma coisa de novo que pode haver, é um conteúdo mais científico”.

A Associação Brasileira de Psiquiatria/ABP publicou a "Nota de Esclarecimento" juntamente com o Conselho Federal de Medicina/CFM, a Federação Nacional dos Médicos/FENAM, a Associação dos Amigos, Familiares e Doentes Mentais do Brasil/ AFDM e a Associação Brasileira de Familiares, Amigos e Portadores de Transtornos Afetivos/ABRATA. A ABP se colocou como representante de toda a categoria psiquiátrica brasileira e negou "qualquer envolvimento com o manifesto e as manifestações contra a nomeação do novo Coordenador Geral de Saúde Mental, Dr. Valencius Wurch" (ABP et al: 2015). Brunet (2015b) informou aos seus leitores do Globo, a partir da manchete "A Associação Brasileira de Psiquiatria apoia ex-diretor de manicômio como coordenador de Saúde Mental”, que a ABP teceu críticas ao atual sistema e se colocou disposta a unir forças com o novo gestor.

A nota da ABP e demais entidades critica o movimento da luta antimanicomial e as coordenações anteriores alinhadas ao movimento, defende um modelo misto de atenção à saúde mental, coaduna com a visão de uma política de saúde mental ancorada em bases científicas e apoia o novo coordenador. As ações do Movimento da Luta Antimanicomial, denominado na nota de LAMA, foram consideradas intempestivas e inadequadas por questionarem um ato soberano do ministro e por impedirem profissionais de trabalharem e pacientes de serem atendidos. Para os proponentes da nota, há quase 30 anos que a Coordenação de Saúde Mental 
adota uma política de viés ideológico que não privilegia a reinserção social e o tratamento médico adequado, uma vez que desativou leitos dos hospitais psiquiátricos e o sistema ambulatorial sem expandir a rede de serviços extra-hospitalares.

As entidades enxergam como componentes do cenário atual: a atenção não qualificada, o aumento de suicídios, mortes e violências. Em contraposição a este cenário, defendem um modelo misto de atenção à saúde mental não centrado exclusivamente em hospitais psiquiátricos (hospitalocêntrico) e nem nos Centro de Atenção Psicossocial/CAPS (capscêntrico). O modelo misto, visto como afinado com os princípios da lei 10.216, se configura como "a implantação de um sistema assistencial hospitalar e extra-hospitalar centrado na atenção básica e no atendimento ambulatorial com equipe multi e interdisciplinar e fortes vínculos com os recursos da comunidade, visando a real reinserção social e a reabilitação funcional dos pacientes com transtornos mentais" (ABP et al., 2015). A nota advoga por uma assistência eficiente, sustentada no rigor da ciência, guiada pela promoção da saúde e a prevenção da doença, e organizada em rede com atenção primária, secundária e terciária.

O ponto de vista de Valencius é resgatado das matérias de jornais. Na reportagem de Filho (2015a) para o jornal O Globo, Valencius contestou as acusações que o colocam como contrário à Reforma Psiquiátrica. Ele afirmou que a lei 10.216 acompanha a Declaração de Direitos Humanos da ONU e questionou como alguém poderia ser contra uma Reforma que ajudou muitas pessoas. No entanto, ele ponderou a necessidade de aprimoramentos na qualificação dos profissionais e na assistência adequada aos pacientes e seus parentes.

Em entrevista à Folha de São Paulo, Valencius afirmou que fizeram uma interpretação errada do seu norte, pois a sua atuação é para aprimorar a política de saúde mental, concordando com o lema "nenhum passo atrás, manicômio nunca mais". Ele contextualizou a sua participação no processo da Reforma Psiquiátrica, explicando que havia sido contra o projeto de lei 3.657, de 1989, porque este não apresentava saída para o fechamento de todos os hospitais psiquiátricos. Dessa maneira, declarou ser a favor da Reforma Psiquiátrica, pois participou nos debates e ajudou na redação da lei 10.216. Referente à sua atuação na Casa de Saúde Doutor Eiras, o psiquiatra afirmou ter trabalhado de 1993 a 1995 a favor de melhores atendimentos e da diminuição das internações permanentes, salientando que muitas pessoas que recebiam a alta voltavam ao hospital por não possuírem local para se abrigarem. O gestor defendeu a abertura de mais leitos psiquiátricos em hospitais gerais como espaços de retaguarda, ponderando que "não existe nenhum país do mundo 
que não tenha leito psiquiátrico. Negar a possibilidade do leito é negar um pedaço da ciência" (Cancian, 2016).

Valencius Wurch tomou posse no dia 7 de Janeiro de 2016 e foi exonerado no dia 9 de Maio de 2016 pela Portaria GM/MS 916 (Brasil, 2016), alguns dias depois da exoneração de Marcelo Castro do Ministério da Saúde. Em termos conjunturais, a sua exoneração foi decorrente da decisão do PMDB de entregar todas as pastas ministeriais para confirmar o rompimento do partido com a Presidente Dilma Rousseff. Porém, para os movimentos da luta antimanicomial, a exoneração de Valencius foi comemorada e considerada uma vitória, pois eles se mantiveram contrários ao gestor e não cessaram de clamar pela sua exoneração.

\section{Polarização e acusações}

As postagens, matérias e notas trazem acusações que despertam o leitor para a existência de uma polarização no campo da saúde mental. As acusações assumem uma importância analítica se vistas, como propôs Velho (1987: 57), enquanto "uma estratégia mais ou menos consciente de manipular poder e organizar emoções, delimitando fronteiras". As acusações são reforçadas por recursos disponíveis em cada meio de divulgação; recursos discursivos, gráficos, de indexação etc. No material apresentado, destacam-se as letras em caixa-alta, as hashtags, as manchetes, os recortes de falas, as interpretações de documentos e a documentação de ações e posições. Todos esses recursos denotam o esforço de organizar emoções e a dimensão política da delimitação de fronteiras, entendendo por política os "processos por meio dos quais indivíduos e grupos tentam mobilizar apoio para seus vários objetivos e, nesse sentido, influenciar as atitudes e ações dos seus seguidores” (Barnes, 2010: 172).

No âmbito das postagens em redes sociais, as palavras e frases em caixa-alta denotam o grito e transportam para os caracteres a emotividade das interações face a face. Por sua vez, as hashtags se configuram como uma maneira de mostrar a amplitude e a capilaridade de uma denúncia, reivindicação ou temática. Silva (2012: 32) explica que as "As pessoas insatisfeitas com questões políticas, econômicas e culturais do local onde vivem, e até mesmo de âmbito global, passaram a criar ações coletivas e movimentos sociais por meio da 'hashtag"'. Para a autora, as hashtags agregam pessoas em torno de insatisfações e se tornam símbolos aglutinadores de uma luta.

A qualificação "ex-diretor de manicômio" figurou em algumas manchetes de jornais e esteve presente no corpo de todas as matérias. Ela tem caráter dúbio de contextualização e acusação, pois ao mesmo tempo em que evoca parte da trajetória profissio- 
nal do psiquiatra, acompanha o temor das expectativas de gestão, calcadas em atuações pregressas. Tal forma de se referir a Valencius sinaliza para a primeira acusação que será resgatada nesse tópico, a que liga o contexto de atuação profissional a uma posição ideológica, equivalendo diretor de hospital psiquiátrico privado e articulador da contrarreforma. A trajetória do profissional é utilizada como um demarcador de fronteiras, pois a expectativa de condução da política nacional parece se configurar enquanto uma extensão da forma como cada profissional se inseriu no campo da atenção em saúde mental, e do seu posicionamento no cenário das lutas políticas mais antigas referentes à maneira como a reforma psiquiátrica deveria ser conduzida.

A fala do então Ministro Marcelo Castro a respeito de uma divisão na Psiquiatria entre dois grupos que se digladiam na contemporaneidade, publicada no jornal Folha de São Paulo, deixa para serem vasculhados os motivos mais profundos dessa cisão, inclusive porque a briga se dá na Psiquiatria e fora dela, historicamente contra ela. Nesse âmbito, a segunda acusação concerne ao posicionamento perante a primeira proposta legal de reforma, o Projeto de lei 3.657, de 1989, sobretudo em relação ao lugar do hospital psiquiátrico na assistência em saúde mental. O posicionamento perante esse projeto tem implicações na maneira como cada grupo se legitima como participante no processo de reforma psiquiátrica, tendo em vista os princípios que eles defendem como norteadores da lei 10.216.

Na nota organizada pela ABRASCO e outras entidades, a rejeição a Valencius é justificada pela postura contrária do gestor ao Projeto de lei 3.657, de 1989, visto como base legislativa para toda a discussão sobre saúde mental que avança durante a década de 1990 e culmina na promulgação da lei 10.216, em 2001. Marcelo Castro afirmou que Valencius havia sido contra a proposta devido à radicalidade do projeto, mas era um profissional a favor da reforma e da lei em vigor. Valencius afirmou ter sido contrário ao referido projeto de lei porque a proposta do fim dos hospitais psiquiátricos não vinha acompanhada de alternativas, porém não concordou com a acusação que o coloca como contrário à reforma psiquiátrica, pois, ao participar das discussões, ele se considera alguém que ajudou no processo de reforma.

O Projeto de Lei 3.657 "dispõe sobre a extinção progressiva dos manicômios e sua substituição por outros recursos assistenciais e regulamenta a internação psiquiátrica compulsória" (Delgado, 1989). A ementa do projeto permite enxergar "a extinção progressiva dos manicômios" como um ponto importante de discórdia e de delimitação de fronteiras. A forma como as pessoas se posicionaram a essa proposta justifica as qualificações de antimanicomial, hospitalocêntrico, capscêntrico, ideológico e 
científico que aparecem no conteúdo das reações e contrarreações. Considerando que todos os que reagiram e contra reagiram à nomeação de Valencius se colocam como pró-reforma psiquiátrica, depreende-se que o posicionamento ao projeto de lei se fundamenta em expectativas diferentes de reforma. Tendo em vista como esse percurso foi narrado, pode-se acrescentar que os tipos diferentes de reforma se apoiavam em concepções que, por um lado, igualavam manicômios, asilos e hospitais psiquiátricos; por outro, os diferenciavam.

De maneira ampla, reforma psiquiátrica se configura como reações por parte da sociedade ao internamento de pessoas consideradas loucas. Para Cavalcanti (1993) e Kinoshita (2016), a cronicidade está no centro da discussão sobre reformas psiquiátricas e o nascimento da Psiquiatria com Pinel já é uma reação à internação dos crônicos, logo, uma proposta de reforma. Amarante (2009) relata que no Brasil, uma forte reação às condições de vida e trabalho nas internações começou, no final da década de 1970, com a organização do MTSM/Movimento dos Trabalhadores em Saúde Mental. Os profissionais denunciaram, por meio de greve, a situação precária de trabalho e as violências nas divisões de saúde mental, tais como "agressão, estupro, trabalho escravo e mortes não esclarecidas” (Amarante, 2009: 52). De algum modo, todos os profissionais e setores da sociedade que denunciaram e reagiram à situação, clamando por mudanças e melhorias, se enquadram como defensores de uma reforma psiquiátrica.

No entanto, Amarante (2009) e Weber (2013) apontam que na década de 1980, após a $8^{\text {a }}$ Conferência Nacional de Saúde e a $1^{\text {a }}$ Conferência Nacional de Saúde Mental, organizou-se o Movimento Nacional da Luta Antimanicomial/MNLA que, influenciado pelo projeto basagliano, pautou-se pela desinstitucionalização. Na Nota da ABP, o MNLA é denominado de "LAMA", termo considerado pejorativo pelos participantes do Movimento e que denota uma tentativa de depreciação. A proposta de desinstitucionalização ataca o saber e o hospital psiquiátrico que, segundo Medeiros (1993), se configurava como um empreendimento econômico da chamada indústria da loucura. O projeto de lei 3.657 é pensado no lastro da desinstitucionalização e, por isso, efetivou a divisão entre aqueles que acreditavam em uma reforma na qual a supressão do hospital era primordial e aqueles que defendiam a importância do dispositivo hospitalar na atenção.

Amarante (1996) contextualiza que a desinstitucionalização, enfocada pela luta antimanicomial, não consiste em mera desospitalização e desassistência e, sim, em uma desconstrução epistemológica do saber médico psiquiátrico e do seu poder 
causador de violências e exclusão que operava via manicômio. A desinstitucionalização não vislumbra reformar ou aperfeiçoar o sistema hospitalar, mas desmontá-lo, fazendo com que a sociedade e a loucura se encontrem para que novas possibilidades de cidadania sejam efetivadas. Portanto, é importante frisar que os defensores de uma reforma psiquiátrica antimanicomial apostam todas as fichas na atenção comunitária e territorializada que, inicialmente, se dá via CAPS. A mobilização “Abraça a RAPS” ilustra bem a defesa da desinstitucionalização, pois abraçou simbolicamente todos os dispositivos comunitários de saúde pelo país contra o retorno do manicômio.

No entanto, os que se colocaram contrários ao projeto de lei, questionam a equivalência entre manicômios, asilos e hospitais. Gentil (1999: 5) defendeu que o projeto de lei continha dois problemas: o primeiro referente à proibição da construção de hospitais psiquiátricos e da contratação de novos de leitos; o segundo referente à proibição da existência de asilos não hospitalares. Para o autor, essa proposta atravancava a modernização do parque hospitalar, sendo que o mais sensato seria impedir a "manutenção dos atuais manicômios" e estimular a "sua substituição por instituições médicas de alta complexidade, chamadas hospitais". Quanto aos asilos, Gentil avalia que a lei tratava a assistência prestada por asilos como internação, o que era uma impropriedade.

O autor propôs, então, uma diferenciação na qual manicômio seria hospital de doidos, hospital configuraria como estabelecimento onde se internam e tratam doentes, e asilo se referiria a um lugar de guarida e proteção para aqueles que não necessitam da internação psiquiátrica. Jorge e França (2001), apresentando a posição da ABP, acompanham Gentil ao afirmarem que a ABP combateu a equivalência entre manicômio e hospital psiquiátrico. Para os autores, "hospitais psiquiátricos de qualidade têm um papel a cumprir dentre os recursos com os quais devemos contar para a proteção de alguns de nossos pacientes” (Jorge e França, 2011: 5).

Dadas as posições de cada grupo perante o exposto no projeto de lei 3.657 e como cada um afirma participar da reforma psiquiátrica brasileira, percebe-se a existência de um embate a respeito do quanto a lei 10.216 é tributária ou completamente diferente do projeto de lei em questão. Para os que acusam Valencius de ser contra a reforma, a lei 10.216 guarda a desinstitucionalização como princípio, sendo tributária do projeto 3.657. Por isso, a atitude contrária ao projeto é estendida e compreendida como contrária à lei em vigor, pois é vista como uma atitude contra um movimento de recusa das estruturas que permitiam as violências 
psiquiátricas. Para Valencius, Marcelo Castro e as entidades que subscrevem a nota da ABP, a lei é completamente diferente do projeto em questão e essa diferença é percebida em sua ementa que não mais trata sobre "a extinção dos manicômios" e, sim, sobre "direitos das pessoas portadoras de transtornos mentais e reorientação da assistência”. A diferença que se percebe em sua ementa é usada para legitimar a participação destes no processo de reforma.

A terceira e última acusação remete-se à violência que cada grupo associa à forma de pensar a atenção em saúde mental do grupo oposto. A reação a Valencius se dá pela sua trajetória em uma instituição denunciada por violências, dentre elas, a internação prolongada, a falta de alimentos e o uso da eletroconvulsoterapia. A atenção centrada nos hospitais e nas internações, o que fundamenta a qualificação de hospitalocêntrico, é usada para desqualificar a possível atuação do gestor e para desabonar aqueles que o apoiam. Nesse caso, há o recurso às violências do passado, não mais permitidas no modelo comunitário e que são vistas como fantasmas a espreita.

Por seu turno, a nota da ABP acusa as coordenações alinhadas ao pensamento antimanicomial de serem capscêntricas e de conduzirem a política de saúde mental por um viés ideológico, reduzindo leitos psiquiátricos devido ao enfoque extra-hospitalar. Tais coordenações são acusadas de desassistência, considerando o número alto de mortes, de pessoas em situação de rua, de encarceramento e suicídios decorrentes de transtornos mentais. Aqui se recorre às violências do presente, utilizando dados não contextualizados para colocar como ineficiente o modelo comunitário e extra-hospitalar.

\section{Dos eventos documentados aos documentos manejados}

As acusações ressaltadas - ligação entre trajetória e expectativa de atuação, posições acerca do projeto de lei que inicia as discussões legislativas sobre a reforma psiquiátrica na nova república, e responsabilização por violências - mostram que a delimitação de fronteiras se nutre de um interessante movimento de documentar as reações e contrarreações, oficializando-as e arquivando-as, e de evocar documentos oficiais, manejando interpretações. Nesse tópico, as reações e contrarreações serão englobadas na categoria “eventos”. O intuito é analisar, à luz de discussões antropológicas acerca dos arquivos e documentos, a documentação dos eventos e o manejo de documentos.

O esforço de olhar para os e através dos eventos e documentos se inspira, ainda, na perspectiva de Laura Nader (1972) acerca dos estudos up. Este esforço se confi- 
gura como uma tentativa de descortinar aspectos e práticas de setores que impactam a vida da população, trazendo informações que indiquem como se dá o controle e as propostas das estruturas institucionais. Uma das colocações de Nader (1972) se refere ao fato dos estudos up permitirem o acesso aos pontos de vistas de gestores, profissionais e usuários a partir da pluralização dos materiais acessados, já que a observação direta e participante das esferas up tem as suas limitações. No presente recorte, a documentação de eventos e o manejo de documentos são uma das trilhas possíveis para se acessar e interpretar a política de saúde mental.

O trabalho de Teixeira (2008) sobre o museu da Fundação Nacional de Saúde demonstra que é possível alcançar as políticas por caminhos não usuais, uma vez que interpreta a política nacional de saúde indígena a partir do acervo de um museu e da forma como ele aparece disposto no espaço museal. Teixeira tece considerações a respeito de disputas na consolidação de um campo político referente à diversidade nas políticas de saúde indígena e sinaliza para o manejo de memórias efetuado nessas disputas.

A pesquisa da autora guarda proximidades com as pesquisas antropológicas dos / nos arquivos, na medida em que essas pesquisas analisam os arquivos como produtores de conhecimento e as suas relações com dimensões macro como a construção do Estado-Nação, a elaboração de políticas públicas, a consolidação de áreas de gestão e setores de conhecimento (Cunha, 2004, 2005; Frehse, 2005; Venancio, 2005). As pesquisas em arquivos avançam na busca de: delimitar e validar interlocutores, enfatizando o processo de construção destes (Frehse, 2005); trazer à tona como o processo de busca informa sobre o objeto e coloca em xeque noções de verdade inicialmente impregnadas em materiais arquivados (Venancio, 2005); e aprofundar a dimensão política da organização dos acervos que são resgatados como validadores de autenticidade em momentos de disputas políticas, identitárias, autorais e culturais (Cunha, 2005).

Paralelo aos e em consequência dos estudos nos arquivos, consolidou-se um enfoque nos documentos. Os documentos começaram a ser apreendidos e vasculhados a partir de um esforço epistemológico de "fazê-los falar" ou de "segui-los" a fim de se alcançar uma pluralidade de vozes e caminhos percorridos, e de proporcionar e controlar circulações de pessoas, bens e objetos. Os documentos se inserem na pesquisa antropológica através das análises de documentos de identificação, de processos, inquéritos, leis, relatórios, contratos etc.

Por um lado, são analisados contra o pano de fundo do Estado, ressaltando como 
eles circulam e fazem com que as pessoas possam circular, de acordo com as premissas legais e as cargas afetivas depositadas neles; e como eles iniciam trânsitos e transações mediadas por órgãos que possuem a legitimidade para torná-los válidos (Navaro-Yashin, 2007; Pinto, 2014). Por outro lado, o interesse recai na forma como são produzidos nas instâncias estatais, nas relações de poder que permeiam as suas construções e se aderem a eles, e no modo como são performados em disputas, fomentando realidades (Vianna, 2002, 2014; Lowenkron e Ferreira, 2014; Maricato, 2015).

O movimento apresentado como "documentação de eventos e manejo de documentos" será decomposto em: evento documentado, documentação de eventos, eventos-documentos e documentos manejados. Essa decomposição é uma tentativa de contornar o apontamento de Hull (2012) sobre o fato das pesquisas antropológicas, mesmo as mais recentes, olharem muito através dos documentos e pouco para eles.

O evento que deu início às reações não foi observado pela pesquisadora e nem pela maior parte das pessoas que se envolveram nas mobilizações contra Valencius, ele foi acessado através de documentos. O aviso da nomeação do gestor ocorreu numa reunião em Brasília com representantes de organizações civis, uma reunião restrita. $\mathrm{O}$ acesso a esse evento se deu pelas postagens nas redes sociais, matérias em jornais, e pelas notas das entidades. Essas três esferas funcionaram como documentação e criaram conteúdos que podem ser acessados, interpretados e até alimentados (no caso das redes sociais) por diversas pessoas, dadas as ferramentas tecnológicas atuais. Assim, o evento tornou-se conhecido porque foi documentado.

A documentação desse evento não se deu somente para informar, ela foi levada a cabo para questionar o ocorrido, influenciando pessoas a reagirem contra o que imediatamente foi interpretado como um retrocesso para política de saúde mental, ou para questionar a política em voga, afirmando a necessidade de balanços e aperfeiçoamentos. A manifestação “Abraça a RAPS” e a "Ocupação fora Valencius” se valeram de diversas formas de registros e compartilhamentos para fazer com que as mobilizações tivessem capilaridade e fossem vistas como de âmbito nacional. Os registros das atividades que ocorriam pelo país, na sala de ocupação, na Esplanada dos Ministérios eram amarrados aos textos e conteúdos audiovisuais criados para o espaço da rede, o que atestava e promovia simultaneamente o alcance das ações contestatórias e descortinava o diálogo entre as esferas estatais e a sociedade civil organizada. A documentação dos eventos comprova a existência e densidade dos mesmos e, como propõe Vianna (2014), ela tem o compromisso com a coerência e a 
obrigação presumida de ser algo que deve permanecer e durar. Tanto as páginas nas redes sociais quanto as matérias publicadas em jornais se configuram como "arquivos digitais" disponíveis para leituras e releituras dos seus conteúdos.

As notas publicadas pelas entidades guardam uma duplicidade, porque elas são eventos que se dão em forma de documentos elaborados para se tornarem públicos e engendrarem diálogos com as esferas da sociedade civil, política e administrativa. O ato de publicá-las marca posições, expõe demandas e delimita grupos. As notas públicas são “eventos-documentos”. Em seus conteúdos é perceptível a evocação e interpretação de outros documentos - projeto de lei, lei e portaria - com o objetivo de justificar decisões, pleitos, motivações e acusações. De acordo com a qualidade de documento público e oficial de entidades que tem trânsitos nas esferas política-administrativas, as notas, seguindo a reflexão de Pinto (2014), repetem a prática de documentar da burocracia, para a qual um documento sempre chama outro documento. É possível perceber semelhanças entre as notas das entidades e a do Ministério da Saúde; todas evocam documentos oficiais para justificar as suas posições.

Os eventos escolhidos para análise nesse artigo carregam a interação entre espaços estatais e sociedade civil organizada, demonstrando que os documentos fazem parte da interação política na qual está em jogo a tomada de decisões que afetam uma população. Seguindo Nader (1972), esses eventos, ocorrendo na interface entre decisões governamentais e contestação social, descortinam o que subsidia as escolhas de gestores e os rumos de políticas públicas. A documentação desses eventos e os documentos oficiais que eles evocam permitem transitar por espaços até então fechados ou pouco frequentados, isto é, permitem a circulação entre os dispositivos de saúde localizados em municípios distantes dos grandes centros e a sala da Coordenação de Saúde Mental em Brasília, colocando juntos registros de ações e textos legislativos e administrativos. Assim, a contestação à nomeação de Valencius interpela o governo e abre as instâncias e práticas estatais para todos aqueles capazes de seguir o que se documenta.

As colocações de Frehse (2005) e Venancio (2005), nos ajudam a compreender que para seguir o que se documenta é primordial não se perder de vista o esforço de delimitar quem são os informantes, e de apontar como o processo de busca constrói o objeto de pesquisa, flexibilizando a verdade que aparentemente impregna os documentos. Os documentos seguidos são aqueles que encontram respaldo no amplo compartilhamento e na ampla divulgação, tornando-se porta-vozes e operadores de uma disputa. A tentativa de se compreender o que fundamentava a disputa 
fez com que se chegasse à forma como a disputa se estruturava, na qual a documentação e a capacidade dos documentos de gerarem adesões ocupam um lugar central. Dessa maneira, foi seguindo acusações que se alcançou a importância dos documentos na disputa em torno dos princípios e da operacionalização da política nacional de saúde mental.

Nas redes sociais, cada grupo noticia e constrói como conteúdo aquilo que lhe interessa para justificar a sua posição e as suas acusações. Os jornais, ao objetivarem cobrir as perspectivas dos grupos e sujeitos envolvidos, colocam em suas matérias a contraposição de visões, delineando e sintetizando a polarização. As notas de repúdio, de esclarecimentos e à imprensa, trazem assinaturas que permitem inferir a organização das entidades em blocos e averiguar se esses blocos ecoam alianças desde o início do processo legislativo de reforma. Considerando que o início do processo legislativo da reforma aparece nas argumentações como um período de cisão, é preciso se ater às verdades que cada grupo busca acessar e construir para justificar as suas posições.

A princípio, a delimitação de informantes é facilitada pela polarização imediata que se percebe nos eventos e documentos, isto é, eles são os que se colocam contra ou a favor de Valencius. No entanto, devido à menção do projeto de lei 3.657, de 1989, intui-se que eles se valem de ideias que vêm sendo nutridas há décadas sobre modelos de atenção e tipos de reforma. Assim, esses informantes da atualidade possuem outros informantes que podem ser identificados com o resgate das narrativas publicadas em livros e periódicos considerados referências no campo da saúde mental. O processo de resgate dessas narrativas, juntamente com a sua relação com os eventos e documentos da atualidade, mostra que é possível identificar informantes em pesquisas com documentos, pois eles são construídos pelos antropólogos a partir dos seus processos de busca, o que foi proposto por Frehse (2005).

Por ecoar ideias, cada grupo maneja documentos de maneira a conseguir operacionalizar a política de saúde mental consonante ao modelo de atenção defendido. $\mathrm{O}$ manejo do documento não se afasta da reflexão de Cunha (2005) sobre os arquivos como validador de autenticidade em tempos de disputas; nesse caso, uma disputa política e de autoria. Nas disputas em torno da Política Nacional de Saúde Mental, os documentos manejados são projeto de lei, lei e portaria. O projeto de lei 3.657, de 1989, já aprofundado no tópico anterior, aparece nesse manejo como ordenador ou não para a lei 10.216. Por um lado, a lei é vista como uma alteração que mantém o seu princípio calcado na desinstitucionalização enquanto uma premissa epistemoló- 
gica; por outro, a lei é vista como um substitutivo que o alterou na sua radicalidade de propor a desinstitucionalização. Como este projeto de lei foi proposto de acordo com as premissas antimanicomiais, o que está em jogo é afirmar ou negar que a lei 10.216 guarda, em seu cerne, essas premissas.

O lugar do hospital psiquiátrico no modelo de assistência é usado para afirmar ou afastar a presença do princípio da desinstitucionalização na lei 10.216. A lei prioriza a atenção comunitária, condiciona a internação somente quando esgotados os recursos extra-hospitalares e proíbe a internação em instituições de caráter asilar (Brasil, 2001). Entretanto, ela não menciona a proibição da construção de hospitais psiquiátricos e da contratação de novos leitos, e, como observa Weber (2013: 16), "não institui mecanismos claros para a progressiva extinção dos manicômios". Dessa maneira, a lei é aberta e permite o seu manejo por grupos que defendem a existência do hospital psiquiátrico, desempenhando um protagonismo médico e técnico, e grupos que colocam em xeque os hospitais psiquiátricos, defendendo a localização do atendimento psiquiátrico na comunidade e se colocando contra a internação prolongada.

A principal estratégia para manejar a lei é trazê-la para o debate de forma fragmentada, enfatizando pontos que justificam posições. A nota da ABRASCO e demais entidades enfatiza a atenção comunitária, extra-hospitalar, e em ambientes sem caráter asilar como os pontos importantes. Já a nota da ABP e demais entidades e a nota do Ministério da Saúde enfatizam que a assistência em saúde mental abarca da atenção ambulatorial aos hospitais, explorando o que a lei deixa em aberto em relação ao uso dos recursos hospitalares quando os recursos extra-hospitalares encontram-se esgotados.

Como reforço no manejo da lei, a nota da ABRASCO evoca a portaria 3.088 de 2011, que "institui a Rede de Atenção Psicossocial para pessoas com sofrimento ou transtorno mental e com necessidades decorrentes do uso de crack, álcool e outras drogas, no âmbito do Sistema Único de Saúde (SUS)” (Brasil, 2011). Essa portaria tem como uma das diretrizes "a ênfase em serviços de base territorial e comunitária, com participação e controle social dos usuários e de seus familiares”. Nela também consta a enfermaria especializada em hospitais gerais e o serviço hospitalar de referência como pontos de atenção hospitalar na rede. Porém, essa "atenção hospitalar” é diferenciada, pois se direciona ao acolhimento em casos graves e de ocorrências de comorbidades de ordem clínica e ou psíquica, com internação restrita a períodos de curtíssima e curta permanência. 
A menção dessa portaria é uma jogada estratégica, pois uma portaria é um ato administrativo que coloca em funcionamento uma lei. As portarias operacionalizam as políticas, mostrando como uma lei é interpretada e colocada em execução. Nesse caso, as entidades manejam a portaria para afirmar não só o óbvio, de que ela está em conformidade com a lei, mas que toda a rede de atenção vem sendo organizada em modelo comunitário e extra-hospitalar calcado no princípio da desinstitucionalização. É esse modelo que se vê ameaçado com a escolha de um gestor com trajetória em hospital psiquiátrico e que defende os hospitais como locus da ciência. As portarias são instrumentos primordiais para se colocar em execução modelos de assistência, por isso, elas precisam ser expostas juntamente com a lei, já que são interpretações da mesma.

Outra dimensão que precisa ser abordada no manejo da lei é ligada à participação em sua construção. Todos os envolvidos na disputa afirmam que a suas propostas seguem o princípio da lei, uma vez que todos cobram o reconhecimento de terem participado do seu processo de construção. Estamos diante de uma disputa de autoria, pois, para alguns, a lei é fruto da luta antimanicomial; para outros, a lei é uma conquista do setor. O reconhecimento ou não da participação na autoria demonstra a relação entre documentos, biografia e afiliação, pois os documentos podem ser percebidos e experienciados como um fenômeno carregado afetivamente, quando manejados em determinadas situações, sobretudo, as de conflitos (Navaro-Yashin, 2007).

A questão da autoria nos permite discorrer a respeito do que Lowenkron e Ferreira (2014) afirmam sobre as relações de poder existentes na produção dos documentos e que se aderem a eles. A lei 10.216, que subsidia e dá os contornos para as propostas de políticas, é fruto de mais de uma década de discussões no legislativo nas quais os interesses políticos e econômicos não podem ser ignorados. A proposta de extinção dos manicômios colocava em xeque o que Medeiros (1993) chamou de "indústria da loucura" e ocasionava perdas monetárias e de poder de barganha para os empresários desse setor, dos donos de hospitais à indústria farmacêutica. Esses fatores, com as negociações políticas, conformam o texto da lei a partir da alteração da ementa do projeto de lei que abre essa discussão. Assim, o que aparece aberto na lei, e que, em termos de gestão, pode ganhar operacionalizações diferentes com as portarias, demonstra as relações de poder que se fixaram nela.

O que está aberto na lei se aproxima do que Vianna (2014) percebeu como os silêncios nos documentos. A autora, em outra ocasião, mostrou que os documen- 
tos são objetos socialmente construídos, mas também socialmente construtores de novas realidades, de capitais de autoridade, de limites e formas de intervenção administrativa (Vianna, 2002). Essa construção de novas realidades pode ser entendida como consequência do que Maricato (2015) chamou de performatização do documento. No caso da lei 10.216, o silêncio, relativo às questões que fundamentam cisões desde a década de 1980, possibilita a sua performatização, garantindo que dois grupos defendam posições diametralmente opostas se valendo do mesmo documento. Faz parte da performatização do documento a menção a outros documentos, uma vez que é possível propor quadros diferentes, dependendo da maneira como os documentos são articulados. Esses quadros diferentes refletem expectativas e justificam as maneiras de operacionalizar as políticas.

\section{Conclusão}

O esforço de acompanhar como a mudança de gestor gerou ações contra e a favor do profissional permitiu um duplo exercício: o de localizar o que fundamenta as posições de cada grupo e o de apontar como uma disputa se estrutura. Com o primeiro exercício, percebeu-se que as posições de cada grupo se baseiam em acusações nas quais as trajetórias dos profissionais são acionadas, tanto no que se refere às suas inserções nos serviços de saúde mental quanto aos seus posicionamentos no processo de reforma psiquiátrica. A responsabilização por violências também compõe o rol dessas acusações, intensificando a combinação das trajetórias com as expectativas em torno da condução da política de saúde mental. O segundo exercício possibilitou perceber que a disputa se estruturou em um movimento de documentar eventos e de manejar documentos, iluminando como os documentos geram adesões e criam realidades.

O esboço que se delineou na tentativa de alcançar as questões importantes da disputa, ganhou nitidez com as elaborações antropológicas sobre documentos. $\mathrm{O}$ olhar antropológico para os documentos recai em fazê-los falar e em segui-los nas diversas tramas que eles proporcionam e são articulados. Tais documentos, mesmo os legislativos e administrativos como leis e portarias, possuem frestas por onde é possível espiar as diversas vozes que os compõem, as relações de poder que neles se afixaram, as biografias e afiliações. Os documentos são linguagem, caminho, prova e chave para uma infinidade de questões que se dão na interface entre instâncias estatais e sociedade; eles permitem acessar as instâncias estatais, iluminando as suas práticas e tomadas de decisões. 
Recebido: 02/04/2018

Aprovado: 16/08/2018

Lilian Leite Chaves é antropóloga, bolsista PNPD/CAPES junto ao Programa de Pós-Graduação em Antropologia Social da UFRN. Contato: lilianlchaves@gmail. com

\section{Referências bibliográficas}

ABRAÇAÇO. 2015. Evento Abraça a RAPS pelo fim do manicômio. Postagem no Facebook. Disponível em: <https://www.facebook.com/events/1684838555072753/>. Acesso em: 14 dez. 2018. AMARANTE, Paulo. 1996. O homem e a serpente: outras histórias para a loucura e a psiquiatria. Rio de Janeiro: Editora Fiocruz.

. 2009. Loucos pela vida. A trajetória da Reforma Psiquiátrica no Brasil. Rio de Janeiro: Editora Fiocruz.

ASSOCIAÇÃO BRASILEIRA DE PSIQUIATRIA et al. 2015. Nota de Esclarecimento. Dezembro de 2015. Disponível em: <http://www.abp.org.br/portal/wp-content/upload/2015/12/nota. pdf>. Acesso em: 14 dez. 2015.

ASSOCIAÇÃO BRASILEIRA DE SAÚDE COLETIVA et al. 2015. Nota pública contra a nomeação deValencius Wurch Duarte Filho para a CGMAD/MS. Dezembro de 2015. Disponível em: <https:// www.abrasco.org.br/site/noticias/institucional/nota-publica-cgmadms/15248/>. Acesso em: 12 dez. 2018.

BARNES, Joan. 2010. Redes sociais e processo político. In: FELDMAN-BIANCO, Bela (org.). Antropologia das Sociedades Contemporâneas: Métodos. São Paulo: Editora UNESP, pp. 171-204.

BRASIL. Presidência da República. Casa Civil. Subchefia para assuntos jurídicos. 2001. Lei 10.216 de 06 de Abril de 2001. Brasília. Disponível em: <http://www.planalto.gov.br/ccivil_03/leis/ leis_2001/l10216.htm>. Acesso em: 20 fev. 2018.

. Ministério da Saúde. Gabinete do Ministro. 2011. Portaria nº 3.088 de 23 de Dezembro de 2011. Brasília, DF, Diário Oficial da União, 26 de dezembro de 2011.

. Ministério da Saúde. 2015. Nota à imprensa: Nomeação do novo coordenador de Saúde Mental, Álcool e Outras Drogas. Brasília, Agência Saúde, 14 de Dezembro de 2015. Disponível em: <http: // www.blog.saude.gov.br/index.php/geral/566-entenda-o-sus/50465-nomeacao-do-novo-coordenador-de-saude-mental-alcool-e-outras-drogas>. Acesso em: 14 dez. 2015.

. Ministério da Saúde. Gabinete do Ministro. 2016. Portaria no 916 de 06 de Maio de 2016. 
Brasília, DF, Diário Oficial da União, 09 de Maio de 2016.

BRUNET, Daniel. 2015(a). Indicação do novo coordenador nacional de saúde mental gera protestos. Blog Emergência. O Globo, 13 de Dezembro de 2015. Disponível em: <http: / /blogs.oglobo. globo.com/blog-emergencia/post/indicacao-do-novo-coordenador-nacional-saude-mental-gera-protestos.html>. Acesso em: 13 dez. 2015.

2015(b). A Associação Brasileira de Psiquiatria apoia ex-diretor de manicômio como coordenador de Saúde Mental. Blog Emergência. O Globo, 15 de Dezembro de 2015. Disponível em: $<$ http: / / blogs.oglobo.globo.com/blog-emergencia/post/associacao-de-psiquiatria-apoia-ex-diretor-de-manicomio-como-novo-coordenador-de-saude-mental.html>. Acesso em: 15 dez. 2015.

CAMBRICOLI, Fabiana. 2015. Ministro nomeia ex-diretor de manicômio para área de saúde mental. Caderno de Saúde. Estadão, 14 de Dezembro, atualizado 15 de Dezembro de 2015. Disponível em: <http://saude.estadao.com.br/noticias/geral,ministro-nomeia-ex-diretor-de-manicomio-para-coordenar-area-de-saude-mental,10000004843>. Acesso em: 15 dez. 2015.

CANCIAN, Natália. 2015. Indicação de ex-diretor de manicômio para a Saúde foi neutra, diz ministro. Cotidiano. Folha de São Paulo, 15 de Dezembro de 2015. Disponível em: <http: / /www1 folha. uol.com.br/cotidiano/2015/12/1719519-indicacao-de-ex-diretor-de-manicomio-para-saude-foi-neutra-diz-ministro.shtml>. Acesso em: 15 dez. 2015.

2016. Alvo de protestos, coordenador de saúde mental diz ser contra manicômios. Cotidiano. Folha de São Paulo, 03 de Março de 2016. Disponível em: <http:/ /www1.folha.uol.com. br/cotidiano/2016/03/1745679-alvo-de-protestos-coordenador-de-saude-mental-diz-ser-contra-manicomios.shtml>. Acesso em: 03 mar. 2016.

CAVALCANTI, Maria Tavares. 1993. Transformação na assistência psiquiátrica ou uma assistência psiquiátrica em transformação. In: RUSSO, Jane e FILHO, João Ferreira (org.). Duzentos anos de psiquiatria. Rio de Janeiro: Relume Dumará: Ed.UFRJ, pp. 145-160.

CHAIB, Júlia. 2015. Troca de nomes para gestão da política de psiquiatria provoca reação. Correio Braziliense, 14 de Dezembro de 2015. Disponível em: <http://www.correiobraziliense.com.br/ app/noticia/brasil/2015/12/14/internas_polbraeco,510561/troca-de-nomes-para-gestao-da-politica-de-psiquiatria-provoca-reacao.shtml>. Acesso em: 14 dez. 2015.

COLLUCCI, Claudia. 2015. Ex-diretor de manicômio conduzirá política de saúde mental no país. Cotidiano. Folha de São Paulo, 14 de Dezembro de 2015. Disponível em: <http: / / www1.folha. uol.com.br/cotidiano/2015/12/1719024-ex-diretor-de-manicomio-conduzira-politica-de-saude-mental-no-pais.shtml>. Acesso em: 14 dez. 2015.

CUNHA, Olívia. 2004. "Tempo imperfeito: uma etnografia do arquivo". Mana, Rio de Janeiro, 10(2): 287-322.

2005. "Do ponto de vista de quem? Diálogos, olhares e etnografias dos/nos arquivos". Revista Estudos Históricos, Rio de Janeiro, v. 2, n. 36, pp. 07-32.

DELGADO, Paulo. 1989. Projeto de Lei nº 3.657/89. Brasília: Câmara dos Deputados.

FILHO, William (a). 2015. Mudança na saúde gera protestos no país. O Globo, 15 de Dezembro de 2015. Disponível em: <http://oglobo.globo.com/brasil/mudanca-na-saude-gera-protestos-no-pais-18295828>. Acesso em: 15 dez. 2015.

(b). 2015. Manifestantes ocupam sala da Saúde Mental em Ministério. O Globo, 15 de 
Dezembro de 2015. Disponível em: <https://oglobo.globo.com/brasil/manifestantes-ocupam-sala-da-saude-mental-em-ministerio-18298934>. Acesso em: 15 dez. 2015

FORMENTI, Lígia. 2015. Ministro da Saúde diz que manterá a indicação de psiquiatra. Saúde. Estadão, 15 de Dezembro de 2015. Disponível em: <http://saude.estadao.com.br/noticias/ geral,ministro-diz-que-mantera-indicacao-de-duarte-filho-para-saude-mental, 10000004941>. Acesso em: 15 dez. 2015.

FREHSE, Fraya. 2005. “Os informantes que jornais e fotografias revelam: para uma etnografia da civilidade nas ruas do passado”. Revista Estudos Históricos, Rio de Janeiro, 2 (36): 131-156.

GENTIL, Valentim. 1999. "A lei Delgado e o futuro da assistência psiquiátrica”. Revista Brasileira de Psiquiatria, São Paulo, 21 (1): 05.

HULL, Matthew. 2012. "Documents and bureaucracy". Annual Review of Anthropology, 41: 251-267.

JORGE, Miguel R; FRANÇA, Josimar MF. 2001. "A Associação Brasileira de Psiquiatria e a Reforma da Assistência Psiquiátrica no Brasil”. Revista Brasileira de Psiquiatria, São Paulo, 23 (1): 3-6. KINOSHITA, Roberto. 2016. Autopoiese e reforma psiquiátrica. São Paulo: Hucitec.

LOWENKRON, Laura; FERREIRA, Letícia. 2014. "Anthropological perspectives on documents: Ethnographic dialogues on the trail of police papers". Vibrant - Virtual Brazilian Anthropology, Brasília, ABA, 11 (2): 76-112.

MARICATO, Glaucia. 2015. Ordenando sujeitos. Histórias performadas da lei 11.520/2007. In: FONSECA, Claudia; MACHADO, Helena (org.). Ciência, identificação e tecnologias de governo. Porto Alegre: Editora da UFRGS/CEGOV, pp. 96-120.

MEDEIROS, Tácito. 1993. Uma história da psiquiatria no Brasil. In: RUSSO, Jane e FILHO, João Ferreira (org.). Duzentos anos de psiquiatria. Rio de Janeiro: Relume Dumará: Ed.UFRJ, pp. 73-84. MÉMORIA DA REFORMA PSIQUIÁTRICA BRASIL E ITÁLIA. 2015. Postagem no Facebook do dia 11 de Dezembro de 2015. Disponível em: <https://www.facebook.com/memoriasaudemental/?hc_ref=ARRfsiv4WjmULUj4Q85dOq3nR8-c7iBIaHpBsaLgrMhbF1mUfC4_BxJcuiUzcJps4W0\&fref $=$ nf $>$. Acesso em: 11 dez. 2015.

NADER, Laura. 1972. Up the anthropologists: perspectives from studying up. In: HYMES, Dell (ed.). Reiventing Atnhropology. New York: Pantheon Books, pp. 284-310.

NAVARO-YASHIN, Yael. 2007. "Make-believe papers, legal forms and the counterfeit: affective interactions between documents and people in Britain and Cyprus". Anthropological Theory, 7: 79-98.

OCUPAÇÃO VALENTE. 2015. Postagem no Facebook do dia 17 de dezembro. Disponível em: <https://www.facebook.com/foravalencius>. Acesso em: 17 dez. 2015.

PINTO, Danilo. 2014. "Um antropólogo no cartório: o circuito dos documentos". Campos, 15 (1): 37-56.

SILVA, Raquel. 2012. Twitter e ciberativismo. O movimento social da hashtag “\#ForaMicarla” em Natal-RN. Dissertação de Mestrado, Universidade Federal do Rio Grande do Norte.

TEIXEIRA, Carla. 2008. "Fundação Nacional de Saúde: a política brasileira de saúde indígena vista através de um museu”. Etnográfica, 12 (2): 323-351.

VELHO, Gilberto. 1987. Individualismo e Cultura. Notas para uma antropologia da sociedade contempo- 
rânea. Rio de Janeiro: Jorge Zahar Editor.

VENANCIO, Ana Teresa. 2005. “As faces de Juliano Moreira: luzes e sombras sobre seu acervo pessoal e suas publicações”. Revista Estudos Históricos, Rio de Janeiro, 2, (36): 59-73.

VIANNA, Adriana. 2002. Quem deve guardar as crianças? Dimensões tutelares da gestão contemporânea da infância. In: SOUZA LIMA, Antônio (org.). Gestar e Gerir. Estudos para uma antropologia da administração pública no Brasil. Rio de Janeiro: Relume-Dumará, pp. 271-312.

. 2014. Etnografando documentos: uma antropóloga em meio a processos judiciais. In: CASTILHO, Sérgio; SOUZA LIMA, Antônio; TEIXEIRA, Carla (org.). Antropologia das práticas de poder: reflexões etnográficas entre burocratas, elites e corporações. Rio de Janeiro: Contra Capa, pp. 43-70. WEBER, César Augusto. 2013. "Rumos da Saúde Mental no Brasil após 1980”. Revista Debates em Psiquiatria. Associação Brasileira de Psiquiatria, Rio de Janeiro, ano 3, 3: 14-22. 
Resumo: Em dezembro de 2015, a nomeação de Valencius Wurch, para o cargo de Coordenador Geral de Saúde Mental, Álcool e outras drogas, reacendeu os debates acerca da atenção em saúde mental no Brasil, fazendo com que a reforma psiquiátrica voltasse à arena das discussões políticas amplamente divulgadas. A nomeação do gestor gerou notas de repúdio, notas de apoio e mobilizações pelo país e nas redes sociais. Estas ações foram documentadas e alcançaram as páginas dos jornais da grande imprensa, demonstrando a existência de uma disputa em torno da política de saúde mental. Nesse artigo, serão apresentadas as ações contrárias e a favor de Valencius, mostrando como elas se fundamentam em acusações que delimitam fronteiras. A análise das ações e acusações permite propor que a disputa em torno da política de saúde mental se organiza a partir de um interessante movimento de documentar eventos e manejar documentos, atualizando embates mais antigos do processo brasileiro de reforma psiquiátrica. Assim, o objetivo principal deste artigo é, à luz das considerações antropológicas sobre documentos, refletir sobre a dimensão documental dessa disputa.

Palavras-chave: saúde mental, política, reforma psiquiátrica, documentos.
Abstract: On December 2015, the appointment of Valencius Wurch as the General Coordinator of Mental Health, Alcohol and Other Drugs, rekindled the debates about mental health care in Brazil, bringing back the theme of psychiatric reform the arena of political discussions widely disseminated. The appointment of the manager generated repudiation notes, notes of support and mobilizations around the country and on the social networks. These actions were documented and reached the pages of the great press newspapers, demonstrating the existence of a dispute about the politics of mental health. This article will be bring the actions against and in favor of Valencius, showing how they are based on accusations that delimit boundaries. The analysis of the actions and accusations makes possible to propose that the dispute around the mental health policy is organized through an interesting movement of documenting events and managing documents, updating older conflicts of the brazilian process of psychiatric reform. Thus, the main objective of this article is, in the light of anthropological considerations about documents, to reflect about the documentary dimension of this dispute.

Keywords: mental health, policy, psychiatric reform, documents. 